\title{
Sistem Informasi UMKM Bengkel Berbasis Web Menggunakan Metode SCRUM
}

\author{
Wahyu Adi Prabowo ${ }^{1}$, Citra Wiguna ${ }^{2, *}$ \\ ${ }^{1}$ Fakultas Informatika, Teknik Informatika, Institut Teknologi Telkom Purwokerto, Purwokerto, Indonesia \\ ${ }^{2}$ Fakultas Informatika, Sistem Informasi, Institut Teknologi Telkom Purwokerto, Purwokerto, Indonesia \\ Email: ${ }^{1}$ wahyuadi@ittelkom-pwt.co.id, ${ }^{2,}{ }^{*}$ citra@ittelkom-pwt.ac.id \\ Email Penulis Korespondensi: citra@ittelkom-pwt.ac.id
}

\begin{abstract}
Abstrak-Penguatan Usaha Mikro Kecil dan Menengah (UMKM) di Indonesia perlu didukung oleh adanya penggunaan dan pengelolaan sistem informasi yang baik. Oleh karena itu para pelaku usaha di harapkan agar dapat menggunakan sebuah strategi operasional yang baik dengan di dukung oleh penggunakaan sistem informasi. Bengkel merupakan salah satu UMKM yang kompleks dengan pelaporan pergudangan dan keuangan yang saling terintegrasi antara satu dengan yang lain. Masalah yang dihadapi pada UMKM Bengkel ini adalah tidak ada sinkronisasi antara stok barang yang ada dengan stok penjualan, begitu juga dengan hal pelaporan baik itu pelaporan gudang maupun pelaporan keuangan. Untuk itu penelitian ini bertujuan untuk membangun sistem informasi UMKM bengkel tire \& rims berbasis web. Dalam membangun sistem ini peneliti menggunakan metode agile software development yaitu SCRUM. Metode ini dipakai karena dalam pengerjaan sistem dapat menyesuaikan kebutuhan product owner yang selalu berubah-ubah dan cepat dalam pengerjaannya. Hasil dari tahapan scrum ini yaitu product $\log$, sprint backlog, sprint dan working increment of the software dapat mengatasi segala permasalahan yang terjadi terhadap masalah waktu, ruang lingkup dan biaya sehingga dalam implementasi pembuatan aplikasi sistem ini dapat mengurangi gap sistem requirement selama proses sprint. Sehingga sistem dapat selesai dibangun sesuai dengan requirement yang dibutuhkan oleh user. Dengan memakai sistem informasi UMKM bengkel ini maka seluruh kegiatan operasional penjualan dapat dimonitor dengan baik dan pelaporan penjualan serta keuangan dapat tersusun secara baik.
\end{abstract}

Kata Kunci: Sistem Informasi; UMKM; Agile; SCRUM; Software Development

Abstract-Strengthening on Micro, Small and Medium Enterprises (MSMEs) in Indonesia needs to be supported by the use and good information systems management. Therefore, business actors are expected to be able to use a operational strategy supported by the use of information systems. Workshop is one of the complex MSMEs with integrated warehousing and financial reporting. The problem faced at this workshop UMKM is that there is no synchronization between the existing stock of goods and the sales stock, as well as reporting both warehouse reporting and financial reporting. For this reason, this study aims to build a web-based MSME information system for tire \& rims workshops. In building this system, researchers used the agile software development method, namely SCRUM. This method is used because the system can adjust to the needs of the product owner, which is always changing and fast in processing. The results of this scrum stage, namely the product log, sprint backlog, sprint and working increment of the software, can resolve all problems that occur with regard to time, scope and cost issues so that in the implementation of making this system application can reduce the system requirements gap during the sprint process. So that the system can be completed in accordance with the requirements needed by the user. By using this workshop's UMKM information system, all sales operational activities can be monitored properly and sales and financial reports can be well structured.

Keywords: Information System; UMKM; Agile; SCRUM; Software Development

\section{PENDAHULUAN}

Seiring berkembangnya suatu bisnis didukung pula oleh perkembangan teknologi dan alat-alat pendukung bisnis yang memadai, Lingkungan bisnis juga tidak terlepas dari teknologi sistem informasi yang memudahkan pekerjaan manusia. Seiring pesatnya perkembangan teknologi sekarang dan didukung dengan alat yang memadai, semakin banyak segala sesuatu menggunakan sistem informasi yang memudahkan semua pekerjaan manusia. Dengan dukungan kemajuan teknologi informasi ini tentu saja para pelaku usaha dimudahkan dalam pengembangan layanan informasi terutama bagi pelaku bisnis [1]. Sistem informasi juga memudahkan pelaku bisnis untuk mengontrol dan mengevaluasi proses bisnis [2], dan juga agar pelaku bisnis dapat mengontrol pelaporan usaha yang efektif dan efisien [3].

Semakin kompleksnya informasi suatu bisnis menuntut sebuah penyelesaian yang terstruktur dan terorganisasi agar penyajian informasi secara cepat dapat dihadirkan dengan baik dan mudah dimengerti. Pertumbuhan Usaha Mikro Kecil dan Menengah (UMKM) di Indonesia dalam 3 tahun terakhir telah tumbuh pesat dapat dilihat pada gambar 1 .

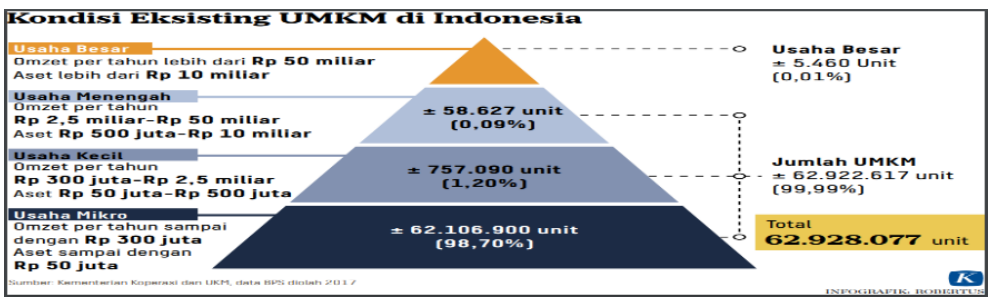

Gambar 1. Pertumbuhan UMKM 2017 (Sumber Kompas) 
UMKM telah memegang peranan penting dalam pertumbuhan perekonomian di Indonesia sehingga UMKM dirasa perlu diberdayakan dan dikembangkan [4]. Pemahaman terhadap teknologi dan sistem informasi berpengaruh positif terhadap kienerja UMKM dan akan berdampak pada peningkatan kinerja secara keseluruhan dan pengendalian terhadap proses bisnis yang baik [5]. Salah satu UMKM yang yang masih belum banyak menggunakan sistem informasi adalah usaha bisnis bengkel tire \& rims. Kurangnya penggunaan sistem informasi pada bengkel tire \& rims mobil bisa menjadi kerugian finansial dalam kinerja bengkel karena masih menyimpan informasi secara manual dan tidak terkendali dalam pelaporannya. Penggunaan teknologi informasi digunakan untuk dapat mempermudah pengelolaan informasi dan mencatat keakuratan informasi [6]. Sistem informasi merupakan gabungan antara pengguna dan sumber daya yang memiliki teknologi informasi untuk mendapatkan jalur komunikasi, memproses tipe transaksi, dan menyampaikan informasi untuk dijadikan pengambilan keputusan oleh manajemen [7]. Sistem informasi merupakan kombinasi orang, hardware,software, jaringan komunikasi dan sumber data yang mengumpulkan, mengubah dan menyebarkan informasi pada organisasi. Sistem informasi memiliki berbagai fungsi seperti : untuk meningkatkan aksesibilitas data secara efektif kepada pengguna, memperbaiki produktivitas aplikasi pengembangan sistem, menjamin tersedianya kualitas dan ketrampilan sistem informasi dan mengembangkan proses perencanaan efektif. Sistem informasi memiliki ciri-ciri baru, tambahan, kolektif, penegas [8].

Penelitian terdahulu yang dilakukan oleh utami et all, bahwa sistem informasi dengan menggunakan website dapat mempermudah user dalam mengontrol dan mengevaluasi bisnis kerupuk UMKM, sehingga dalam kegiatannya mempermudah dalam penyusunan laporan keuangan UMKM [9]. Widiastuti et all melakukan penelitian dengan membangun sistem informasi makanan ringan menggunakan metode waterfall. Dengan membangun sistem informasi maka user dapat mencatat segala hasil produksi dan transaksi agar menjadi lebih efektif dan efisien. [10]. Penelitian lain tentang sistem informasi UMKM juga dilakukan oleh Prabowo et all dengan membangun sistem informasi dinas koperasi UMKM DIY dengan menggunakan metode waterfall. Dengan menggunakan sistem ini user dapat dengan mudah untuk melakukan pendataan UMKM secara uptodate, memudahkan manajemen dalam konsultasi, dan secara cepat dapat melakukan pencarian data UMKM sesuai dengan kriterianya [11].

Bengkel tire \& rims mobil "BRAGA" yang berdiri pada tahun 2010 hingga saat ini telah berusia 10 tahun merupakan UMKM yang bergerak dalam penyediaan ban mobil dan velg mobil. Sebagai tempat untuk merenovasi sebuah kendaraan beroda empat, bengkel ini banyak sekali part-part kendaraan yang tersimpan di dalam Gudang dan tidak tercatat dengan baik dan masih bersifat manual di dalam Microsoft excel dan pegawai terkadang masih belum bisa membedakan nama-nama barang dan kode barang. Tentu saja permasalahan ini akan membuat laporan keuangan dan laporan persediaan barang akan menjadi tidak terkendali dengan baik. Pertumbuhan lingkungan bisnis yang perkembangannya sangat cepat, para pelaku usaha harus dituntut mampu menyesuaikan lingkungannya dengan kondisi di era modernisasi sekarang ini[12]. Kemampuan bersaing sebuah perusahaan dinilai berdasarkan pada informasi yang berkualitas. Informasi yang berkualitas akan terbentuk dari adanya sistem informasi (SI) yang dirancang dengan baik. Pemanfaatan SI yang efektif dan didukung oleh sumber daya yang mampu mengoperasikannya dapat meningkatkan kinerja perusahaan maupun individu yang bersangkutan [13].

Sistem informasi bengkel belum diimplementasikan oleh bengkel ini, untuk membantu kinerja yang efektif dan efisien maka solusi dari pelaksanaan penelitian ini adalah dengan membangun sistem informasi pada bengkel dengan menggunakan metode scrum. Menggunakan metode scrum merupakan kegiatan tim development. Pembangunan sebuah aplikasi dengan metode scrum tidak hanyak dilihat dari keseluruhan tim development, tetapi juga dilihat dari keterlibatan seluruh aspek organisasi [14]. Dengan adanya keterlibatan pihak pemangku kepentingan dalam organisasi maka tim dapat mengantisipasi perubahan-perubahan yang terjadi selama proses pengembangan sistem [15]. Dengan menggunakan metode scrum ini maka tim development dapat menghasilkan sistem informasi yang berkualitas dalam waktu yang singkat. [16]. Untuk itu dalam pembangunan Sistem informasi bengkel tire \& rims ini membutuhkan metode scrum agar dalam pelaksanaannya menjadi efektif dan efisien dan sistem dapat membantu pencarian stock ban dan velg di gudang bengkel. Maka dengan menerapkan sistem informasi ini diharapakan dapat membantu pihak - pihak yang terikat secara langsung atau pun tidak langsung.

\section{METODOLOGI PENELITIAN}

Penelitian ini dilakukan untuk melakukan pengembangan sistem informasi bengkel dengan menggunakan metode Agile Software Development yaitu scrum. Scrum merupakan sebuah kerangka kerja untuk menyelesaikan pekerjaan-pekerjaan yang kompleks dan selalu berubah. Kerangka Scrum digunakan untuk menjawab persoalan adaptif yang kompleks, menghasilkan kreatifitas dan inovasi[17]. Sprint merupakan inti dari metode Scrum yang merupakan batasan waktu yang dalam 1 bulan atau kurang dimana sebuah ikremen yang selesai, berfungsi dan berpotensi untuk dikembangkan. Proses sprint biasanya memiliki durasi waktu yang konsisten. Jika proses sprint tahap pertama sudah selesai maka dilanjutkan dengan proses sprint selanjutnya [18]. Tahapan Scrum ini terdiri 


\section{JURNAL MEDIA INFORMATIKA BUDIDARMA}

Volume 5, Nomor 1, Januari 2021, Page 149-156

ISSN 2614-5278 (media cetak), ISSN 2548-8368 (media online)

Available Online at https://ejurnal.stmik-budidarma.ac.id/index.php/mib

DOI 10.30865/mib.v5i1.2604

dari product log, sprint backlog, sprint, working increment of the software [17].Tahapan-tahapan penelitian dalam metode agile scrum ini dibagi menjadi beberapa tahapan, yang dapat dilihat pada gambar 2, yaitu

1. Product Log

Product log merupakan sebuah list daftar dari kebutuhan-kebutuhan yang perlu diketahui dan dipahami saat ini [17]. Pada tahapan ini peneliti melakukan pendefinisian dari kebutuhan pelaku bisnis, pendeskripsian kebutuhan ini bersifat dinamis yang sering kali kebutuhan dapat berubah-ubah.

2. Sprint Backlog

Sprint backlog adalah daftar-daftar dari backlog yang dipilih sesuai dengan kebutuhan dari pelaku usaha agar dapat mencapai sprint goal [17]. Pada tahapan ini pekerjaan sprint backlog dilakukan oleh peneliti dan pelaku usaha agar pembangunan sistem informasi bengkel ini mencapai sprint goal dan memastikan agar ada peningkatan dan perbaikan berkelanjutan.

3. Sprint

Sprint dilakukan untuk menyelesaikan pekerjaan sistem informasi bengkel agar nilai dari sistem informasi ini dapat meningkat dan memonitoring pekerjaan-pekerjaan dalam produk backlog

4. Working increment of the software

Pada tahapan ini adalah proses penyelesaian sprint, dan pada tahapan ini kondisi harus bisa digunakan oleh pelaku usaha.

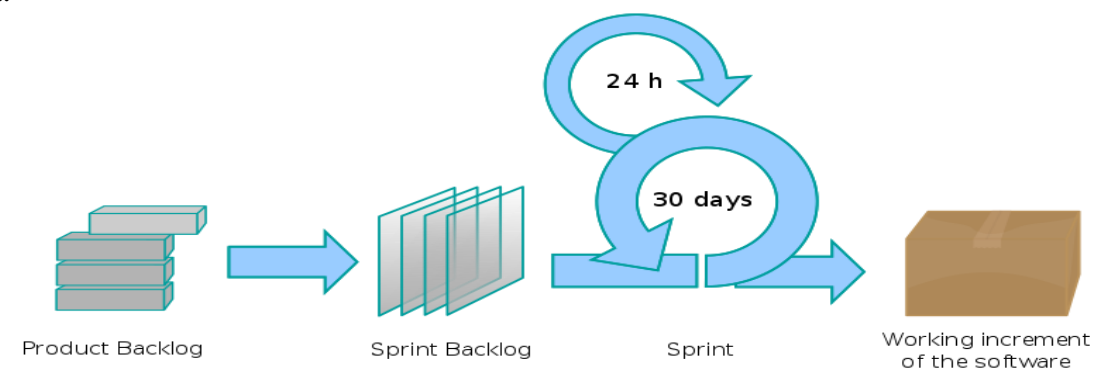

Gambar 2. Tahapan penelitian proses Scrum (sumber : The Scrum Guide) [17]

\section{HASIL DAN PEMBAHASAN}

\subsection{Product Backlog}

Dalam product backlog peneliti menyusun prioritas kebutuhan-kebutuhan sistem informasi yang penting untuk dikembangkan dalam sistem ini yang dapat dilihat pada tabel 1.

Tabel 1. Product Backlog

\begin{tabular}{lll}
\hline No & \multicolumn{1}{c}{ Kebutuhan } & Prioritas \\
\hline 1 & Input Data barang & User Aktif \\
2 & Input Data Pelanggan & User Aktif \\
3 & Input Data Karyawan & User Aktif \\
4 & Laporan Penjualan & User Aktif \\
\hline
\end{tabular}

\subsection{Sprint Backlog}

Sprint backlog yang disusun oleh peneliti bertujuan untuk mengetahui lama pekerjaan dilakukan berdasarkan sumberdaya yang dialokasikan agar sistem ini dapat diselesaikan secara cepat agar desain konseptual yang akan di susun menjadi jelas. Timeline pekerjaan sprint backlog dapat dilihat pada tabel 2.

Tabel 2. Timeline Sprint Backlog

\begin{tabular}{lccc}
\hline Peran Tim & Jumlah hari kerja sprint & Jumlah Jam/Hari & Total Jam Sprint \\
\hline Project Manager & 7 & 5 & 35 \\
(Scrum Master) & & & 56 \\
System Analyst & 8 & 7 & 56 \\
Programmer 1 & 8 & 7 & 56 \\
Programmer 2 & 8 & 7 & 5 \\
\hline
\end{tabular}

\subsection{Sprint}

Pada tahapan sprint, desain konseptual terbentuk dari abstraksi lalu diterjemahkan ke dalam produk nyata. Model ini mencerminkan sesuatu yang nyata dari hasil proses-proses analisa yang telah dilakukan sebelumnya [19], [20]. Desain konseptual ini dibentuk berdasarkan dari hasil analisa kebutuhan pemilik usaha pada proses sprintini. Pada tahap konseptual ini dibutuhkan diagram konteks yang dapat menunjukkan proses -proses kegiatan sistem 
JURNAL MEDIA INFORMATIKA BUDIDARMA

Volume 5, Nomor 1, Januari 2021, Page 149-156

ISSN 2614-5278 (media cetak), ISSN 2548-8368 (media online)

Available Online at https://ejurnal.stmik-budidarma.ac.id/index.php/mib

DOI 10.30865/mib.v5i1.2604

informasi. Diagram konteks merupakan gambaran sebuah hubungan operasional sistem dengan entitas di luar sistem [21].Terdapat 2 entitas yang saling berhubungan, yaitu admin dan karyawan. Entitas Admin bertugas untuk mengatur data barang dan informasi lain yang berhubungan dengan penjualan barang-barang dan data profile karyawan. Entitas karyawan bertugas untuk melakukan seluruh inputan dari transaksi penjualan. Diagram konteks ini dapat dilihat pada gambar 3.

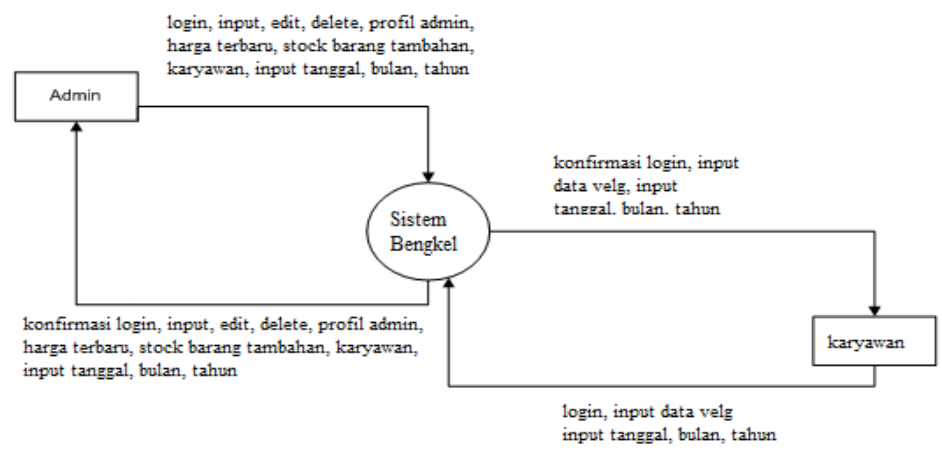

Gambar 3. Diagram Konteks

Dalam perancangan sistem peneliti membuat sebuah activity diagram dalam setiap entitasnya dan dibutuhkan gambaran rencana pengembangan sistem informasi yang dibentuk ke dalam diagram, yang dapat dilihat pada gambar 4.

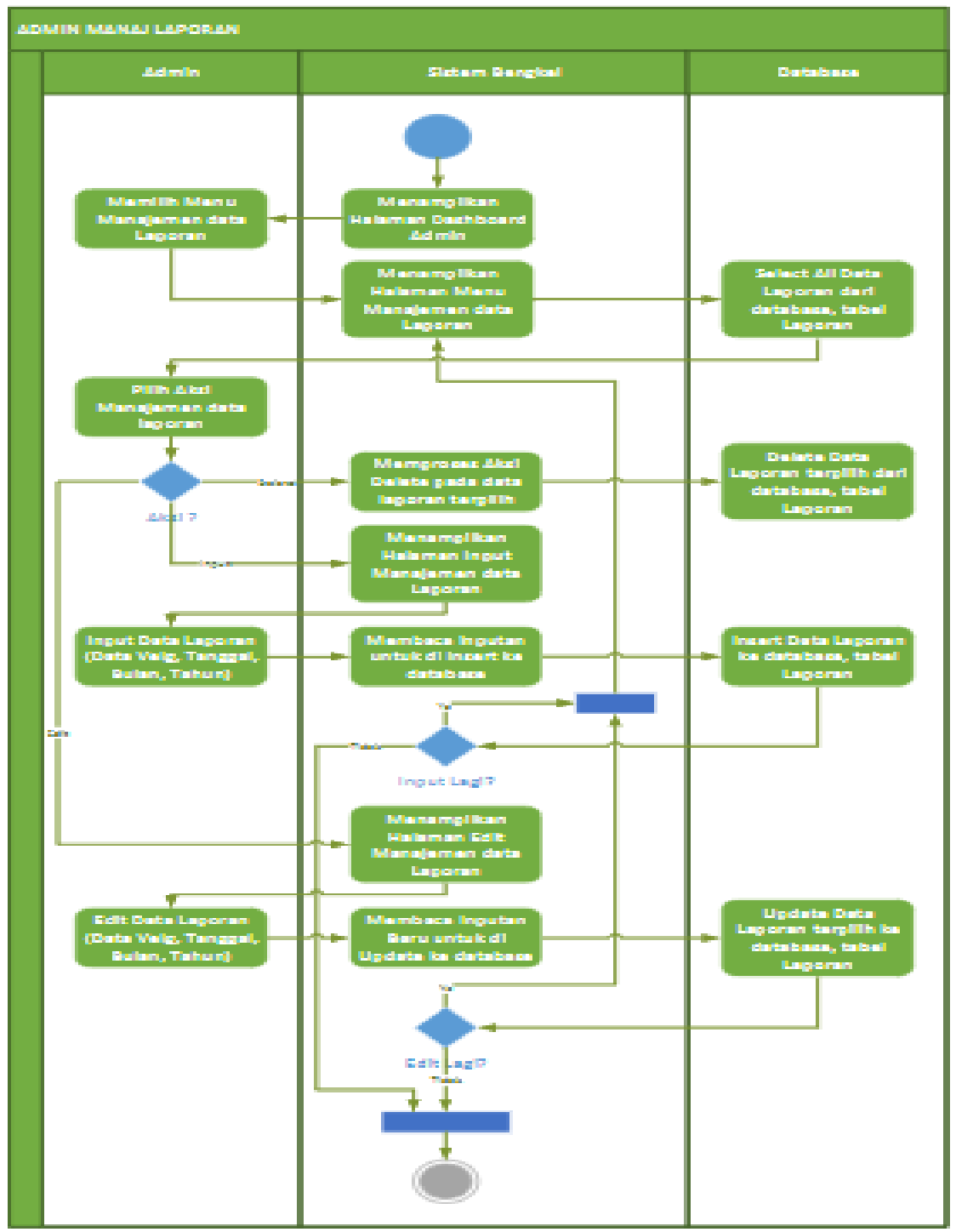

Gambar 4. Admin Manajemen Laporan

Wahyu Adi Prabowo, Copyright (C2021, MIB, Page 152 
JURNAL MEDIA INFORMATIKA BUDIDARMA

Volume 5, Nomor 1, Januari 2021, Page 149-156

ISSN 2614-5278 (media cetak), ISSN 2548-8368 (media online)

Available Online at https://ejurnal.stmik-budidarma.ac.id/index.php/mib DOI 10.30865/mib.v5i1.2604

\subsection{Working increment of the software}

Pada tahapan implementasi dalam pembuatan sistem informasi bengkel tire \& rims ini, peneliti menggunakan bahasa pemrograman PHP untuk Graphic User Interface dan database MySQL sebagai query sebagai penyimpanan data dan informasi dari sistem. Tahapan Implementasi disini merupakan tahap atas hasil yang telah dirancang dari Sistem Informasi bengkel tire \& rims yang akan dibuat. Sistem Informasi bengkel velg mobil ini akan diopersikan dengan sebenarnya sesuai dengan tujuan yang telah diharapkan pada tahapan sebelumnya. Berikut ini adalah penjabaran antarmuka dari Sistem Informasi bengkel tire \& rims pada tahapan working increment of the software:

Pada halaman administrator, admin mempunyai hak untuk mengganti password dan username admin, menambah dan menghapus id karyawan, menambahkan stok barang, menambah type tipe barang dan merk barang. Halaman login dapat dilihat pada gambar 5

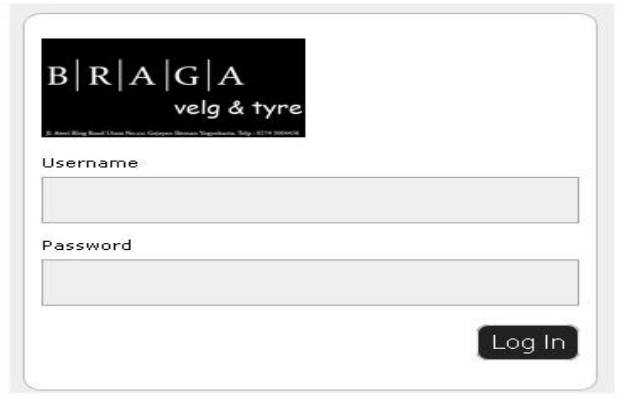

Gambar 5. Halaman Login

Gambar 6 merupakan halaman detail home yang berisi tentang data-data informasi terkait dengan stok barang, data pembelian dari tiap-tiap transaksi, data laporan barang, laporan penjualan serta keuangan, dan data karyawan.

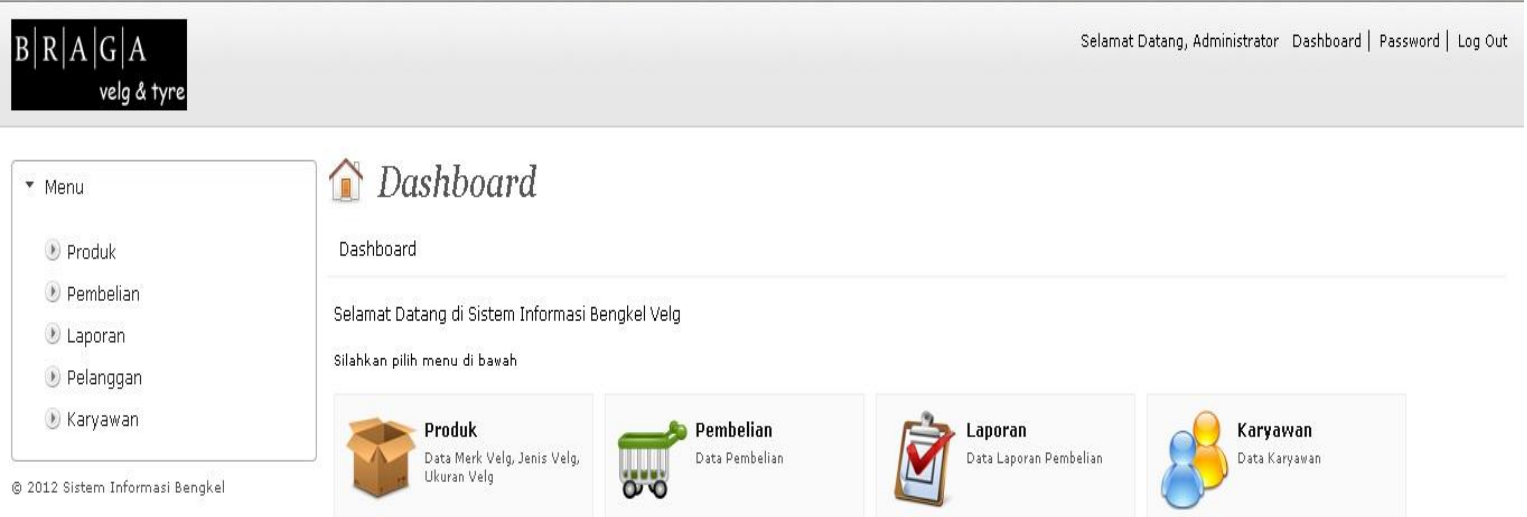

Gambar 6. Halaman Home

Pada halaman produk yang dapat dilihat pada gambar 7, terdapat beberapa data yang harus diinputkan yaitu merk, type, size dan harga. Pada halaman produk ini juga terdapat tombol delete dan add yang berguna untuk mengurangi dan menambah jenis barang.

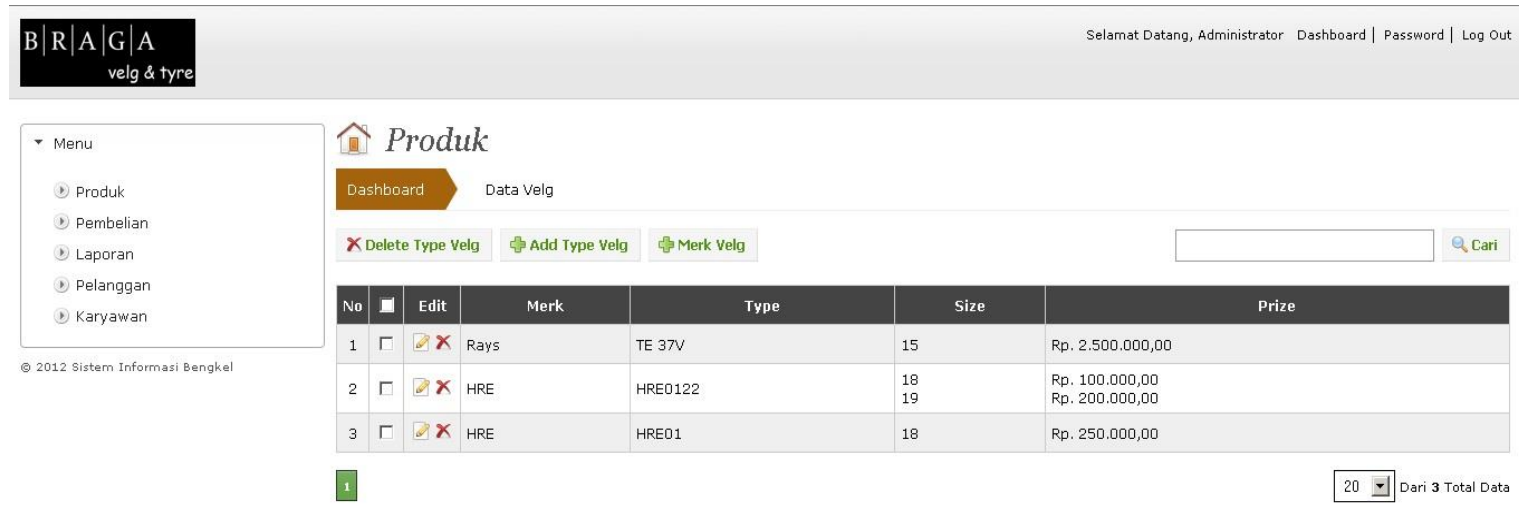

Gambar 7. Halaman Produk 
JURNAL MEDIA INFORMATIKA BUDIDARMA

Volume 5, Nomor 1, Januari 2021, Page 149-156

ISSN 2614-5278 (media cetak), ISSN 2548-8368 (media online)

Available Online at https://ejurnal.stmik-budidarma.ac.id/index.php/mib DOI 10.30865/mib.v5i1.2604

Halaman pembelian pada gambar 8, terdapat beberapa informasi penjualan terkait dengan merek barang, tipe barang, gambar barang, ukuran dan harga barang. Sistem informasi ini akan terhubung ke dalam database laporan penjualan sehingga dalam tiap-tiap transaksi akan dapat dilihat oleh admin.

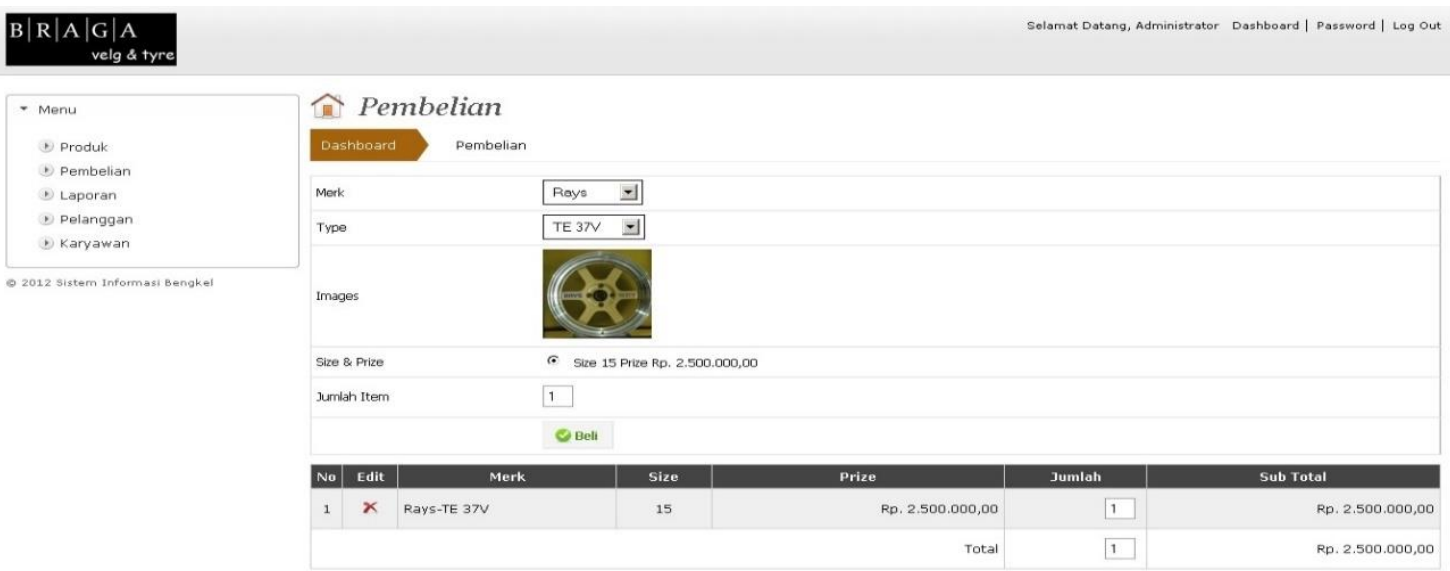

Gambar 8. Halaman Pembelian

Dalam halaman transaksi pembelian pada gambar 9 terdapat halaman form untuk mengisi data pelanggan, data ini akan berfungsi untuk menyimpan data pelanggan lama dan pelanggan baru. Data ini berfungsi untuk pelaku bisnis bengkel agar bisa melakukan promosi langsung kepada pelanggan. Data pelanggan dapat dilihat pada gambar 10 .

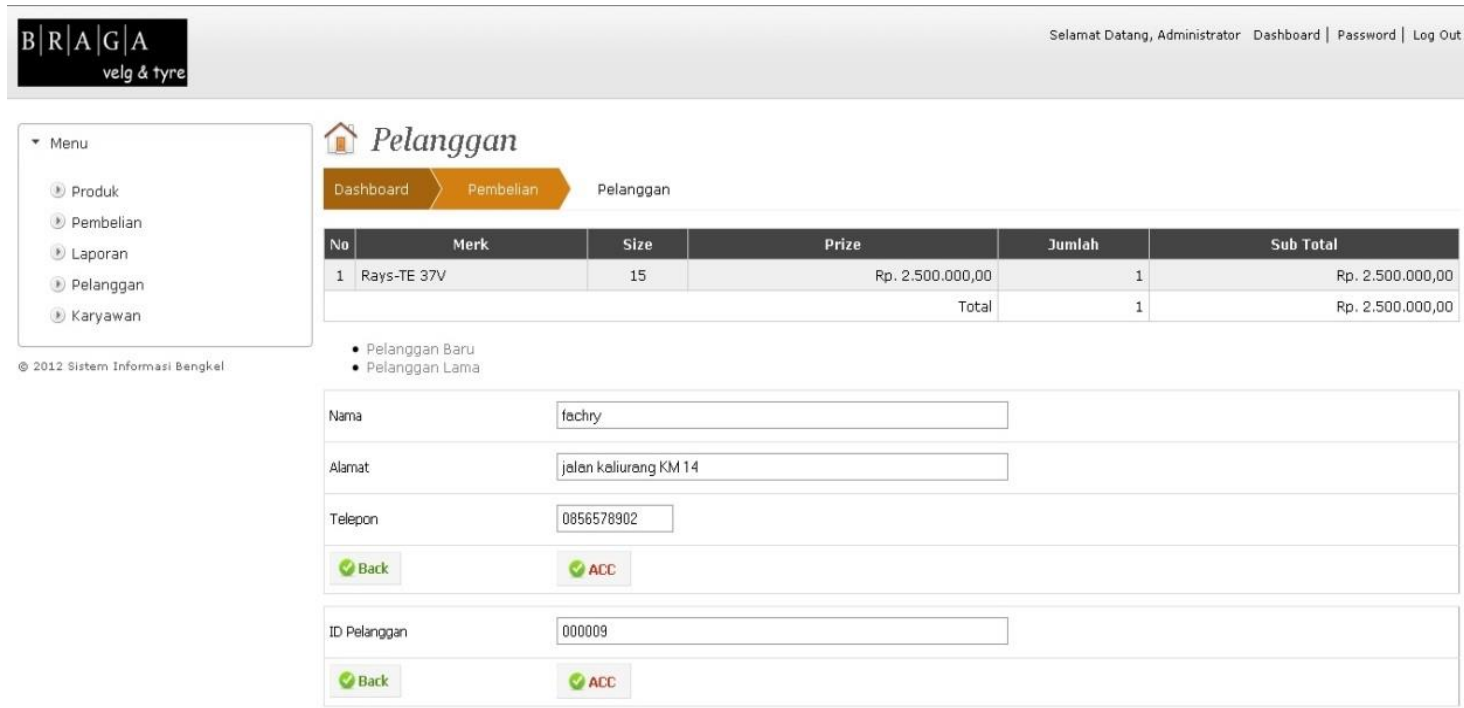

Gambar 9. Halaman Pelanggan

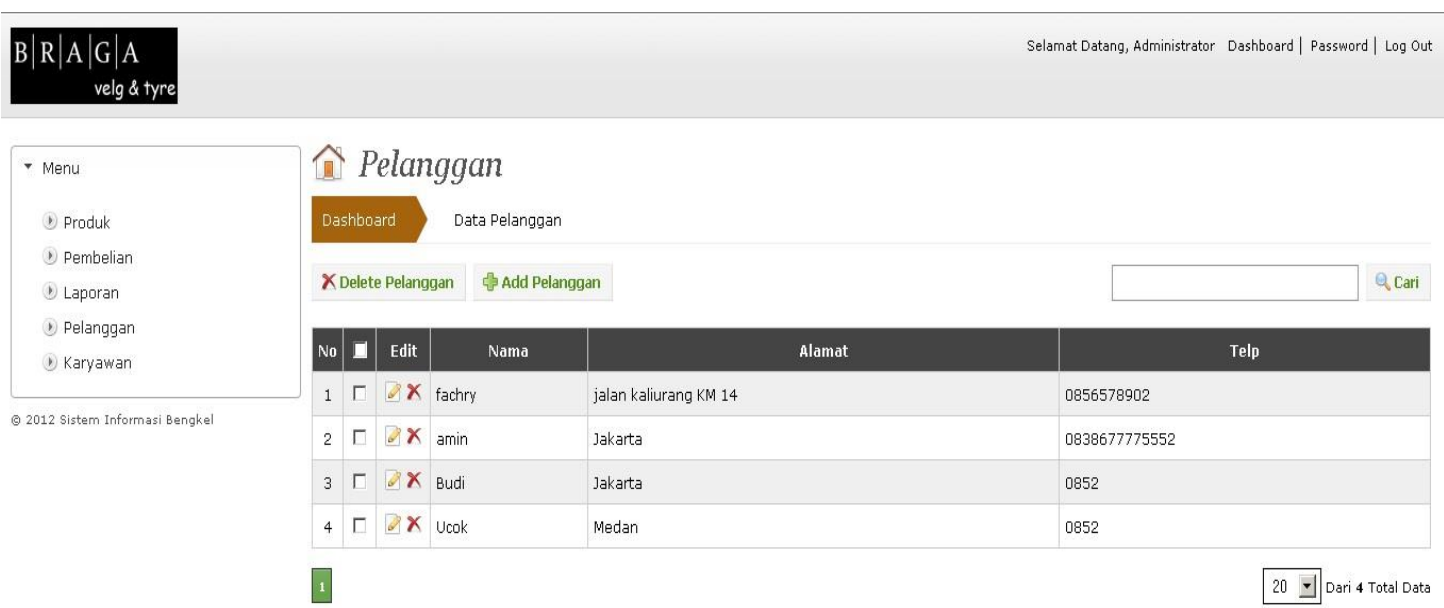

Gambar 10. Data Pelanggan

Wahyu Adi Prabowo, Copyright (C2021, MIB, Page 154 
Halaman laporan pada gambar 11 adalah halaman untuk menampilan data-data penjualan beserta laporan penjualan yang bisa di ekspor kedalam format pdf.

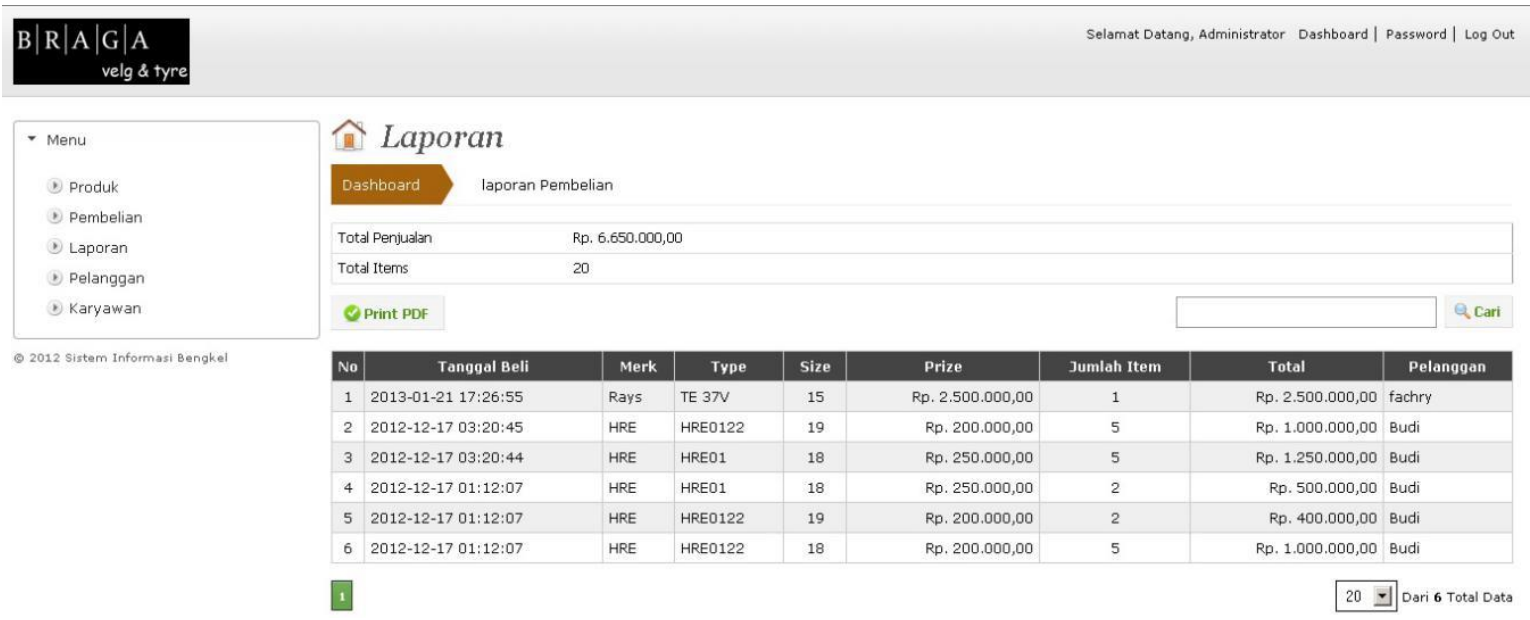

Gambar 11. Halaman Laporan

\section{KESIMPULAN}

Berdasarkan hasil penelitian yang dilaksanakan dengan membangun sistem informasi UMKM Bengkel ini dapat disimpulkan bahwa dengan memakai sebuah sistem informasi UMKM bengkel ini maka seluruh kegiatan operasional penjualan dapat dimonitor dengan baik dan dapat membantu pemilik usaha dalam mencatat laporan transaksi-transaksi penjualan secara efektif dan efisien. Tahapan proses scrum yang terdiri dari product log, sprint backlog, sprint dan working increment of the software dapat mengatasi segala permasalahan dalam implementasi membangun sistem informasi UMKM bengkel ini. Terhadap masalah waktu, ruang lingkup, dan biaya dapat terkoordinasi dengan baik dengan para pihak-pihak yang berkepentingan sehingga hasil dari sistem ini dapat implemetasikan sesuai dengan kebutuhan pengguna. Gap analisis yang terjadi selama pembuatan sistem informasi ini telah diidentifikasi dari awal proses pada tahapan product log dan penyesuaian dengan aplikasi yang akan dibangun dapat lebih adaptif dengan perubahan-perubahan yang terjadi selama proses tahapan sprint. Komunikasi antara peneliti dan produk owner dilakukan secara intensif setiap hari agar mengurangi adanya gap sistem requirement selama proses sprint. Sistem ini dibuat dibuat secara open source agar dapat dilakukan pengembangan lebih lanjut terhadap sistem informasi UMKM bengkel tire \& rims ini. Dalam menggunakan metode scrum ini, sistem dibuat berdasarkan kebutuhan sekarang dan menitik beratkan pada pelaporan operasional penjualan dan dokumentasinya.

\section{REFERENCES}

[1] N. Aini and S. Wicaksono, "Pembangunan Sistem Informasi Perpustakaan Berbasis Web menggunakan Metode Rapid Application Development (RAD) (Studi pada : SMK Negeri 11 Malang),” J-Ptiik.Ub.Ac.Id, vol. 3, no. 9, p. 9, 2019, [Online]. Available: http://j-ptiik.ub.ac.id/index.php/j-ptiik/article/download/6236/2996.

[2] A. T. Helmi, I. Aknuranda, and M. C. Saputra, "Analisis Dan Pemodelan Proses Bisnis Menggunakan Business Process Improvement (BPI) Pada Lembaga Bimbingan Belajar (Studi Kasus : Lembaga Bimbingan Belajar Prisma),” J. Pengemb. Teknol. Inf. dan Ilmu Komput. Univ. Brawijaya, vol. 2, no. 10, pp. 4184-4191, 2018.

[3] ud Effendi, E. Cahyono, and U. Effendi, "Perancangan Sistem Informasi Efektivitas dan Efisiensi Peralatan Berbasis Website (Studi Kasus di PT Kediri Matahari Corn Mills, Kediri) Design of Web-Based Equipment Effectiveness and Efficiency Information System (Case Study at PT Kediri Matahari Corn M,” Ind. J. Teknol. dan Manaj. Agroindustri, vol. 5, no. 3, pp. 159-168, 2016.

[4] Mutmainnah and H. Mulyono, "Analisis Dan Perancangan Sistem Informasi Promosi Berbasis Web Pada," J. Manaj. Sist. Informasi, STIKOM Din. Bangsa, vol. 3, no. 4, pp. 845-855, 2018.

[5] I. Endiana and I. Sudiartana, "Pengaruh Pemahaman Dan Penerapan Sistem Informasi Terhadap Kinerja Umkm Pengrajin Genteng Di Kabupaten Tabanan,” J. Ilmu Manaj. Mahasaraswati, vol. 6, no. 1, p. 101983, 2016.

[6] N. Setiadi and R. Setiawan, "Pengembangan Aplikasi Penjualan Sparepart di Bengkel Anugrah Jaya Motor Berbasis Desktop," J. Algoritm., vol. 13, no. 2, pp. 399-406, 2017, doi: 10.33364/algoritma/v.13-2.399.

[7] F. Acai Sudirman, Muttaqin, Ramen A. Purba, Alexander Wirapraja, Leon A. Abdillah and J. S. Fatimah Nur Arifah, Julyanthry, Ronal Watrianthos, "Sistem Informasi Manajemen," in Sistem Informasi Manajemen, 1st ed., Alex Rikki, Ed. Indonesia: Yayasan Kita Menulis, 2020, p. 160.

[8] R. I. Elisabet Yunaeti Anggraeni, "Pengantar Sistem Informasi," in Pengantar Sistem Informasi, 1st ed., Indonesia: ANDI Yogyakarta, 2017, p. 148.

[9] I. D. Utami, I. Santosa, R. Annisa, I. R. Simanjuntak, U. A. Permatasari, and N. Faizah, "Sistem Informasi Manajemen Berbasis Web pada Usaha Mikro Kecil Dan Menengah (UMKM) (Studi Kasus: UMKM Sumber Jokotole, Socah, 
ISSN 2614-5278 (media cetak), ISSN 2548-8368 (media online)

Available Online at https://ejurnal.stmik-budidarma.ac.id/index.php/mib

DOI 10.30865/mib.v5i1.2604

Bangkalan)," INTEGER J. Inf. Technol., vol. 4, no. 1, pp. 1-10, 2019, doi: 10.31284/j.integer.2019.v4i1.493.

[10] H. Widiastuti and A. Fatmawati, "Production Information System Production of Usaha," J. Insypro, vol. 4, no. 2, pp. 17, 2019.

[11] A. S. Prabowo and L. Syafirullah, "Rancang Bangun Sistem Informasi Usaha Mikro Kecil Menengah Studi Kasus Dinas Koperaso UMKM Daerah Istimewa Yogyakarta," vol. 9, no. 2, pp. 2-6, 2018.

[12] S. Rosimah and J. Siswanto, "Kebutuhan Sistem Organisasi Yang Adaptif Dan Rekonfiguratif Untuk Menghadapi Perubahan Lingkungan Eksternal Pada Perusahaan Telekomunikasi,” pp. 1-9, 2012.

[13] N. P and Dedi, “Analisis Faktor-Faktor Yang Mempengaruhi Kinerja Sistem Informasi Akuntansi (Sia)," Maj. Ilm. Sultan Agung, vol. 49, no. 125, 2019.

[14] M. N. Fuadi, "ScrumBut — Deviasi Implementasi Scrum di Sektor Industri ( Studi Kasus : Ralali )."

[15] T. Rizaldi, "Implementasi Metodologi SCRUM dalam Pengembangan Sistem Pembayaran Elektronik Pada Usaha Mikro Kecil Menengah," Cereb. Cortex, vol. 27, no. 1, pp. 485-495, 2017, [Online]. Available: https://publikasi.polije.ac.id/index.php/prosiding/article/view/236.

[16] I. Mahendra and D. T. Eby Yanto, "Sistem Informasi Pengajuan Kredit Berbasis Web Menggunakan Agile Development Methods Pada Bank Bri Unit Kolonel Sugiono,” J. Teknol. Dan Open Source, vol. 1, no. 2, pp. 13-24, 2018, doi: 10.36378/jtos.v1i2.20.

[17] K. Schwaber and J. Sutherland, "The Scrum Guide | Scrum Guides," https://www.scrumguides.org/docs/scrumguide/v2017/2017-Scrum-Guide-US.pdf, 2017. .

[18] Lesamana, I Putu Dody, "Manajemen proyek dengan scrum," in Manajemen proyek dengan scrum, 1st ed., Yogyakarta: CV Absolute Media, 2019, p. 185.

[19] X. Feng and H. Liu, "Design of the Database of Library Information," Int. J. Database Theory Appl., vol. 6, no. 2, pp. 31-38, 2013.

[20] H. H. Hawkins, S. K. Young, K. C. Hubert, and P. Hallock, "Conceptual database modeling for understanding and developing information management applications.," Radiographics, vol. 21, no. 3, pp. 781-787, 2001, doi: 10.1148/radiographics.21.3.g01ma07781.

[21] Eka Iswandy, "Sistem Penunjang Keputusan Untuk Menentukan Penerimaan Dana Santunan Sosial Anak Nagari Dan Penyalurannya Bagi Mahasiswa Dan,” TEKNOIF, vol. 3, no. 2, pp. 70-79, 2015. 